\title{
Internal Erosion Breach Model Review and Validation
}

\author{
Mark Morris $^{1}$ and Jean-Robert Courivaud ${ }^{2}$ \\ ${ }^{1}$ HR Wallingford, Howbery Park, Wallingford, Oxfordshire OX10 8BA, United Kingdom \\ ${ }^{2}$ Electricité de France, Centre d'Ingénierie Hydraulique, Savoie Technolac, 73290 La Motte-Servolex, France.
}

\begin{abstract}
Predicting breach erosion processes is essential for the effective risk management of both dams and levees. Following the success of an earlier initiative to assess the performance of breach models for predicting overflow erosion of dams and levees a new project has been launched to investigate the performance of industry models predicting breach formation initiated through internal erosion. The overall conclusions from this work will be guidance for industry practitioners regarding the types, availability, and likely performance of industry applicable internal erosion breach prediction models. This paper presents details of progress achieved with the performance evaluation programme at the start of 2021, which is roughly halfway through the $2 \frac{1}{2}$ year overall programme.
\end{abstract}

\section{Introduction}

Predicting breach erosion processes is essential for the effective risk management of both dams and levees. Following the success of an earlier initiative to assess the performance of breach models for predicting overflow erosion of dams and levees (i.e., the CEATI Dam Safety Interest Group Breach Modelling Project (Bureau of Reclamation, 2017)), a new project has been launched to investigate the performance of industry models predicting breach formation initiated through internal erosion.

The project was initiated by Electricité de France (EDF) and started mid-2019, with a planned duration of $\sim 2$ $1 / 2$ years. The COVID-19 pandemic has affected the schedule and working approach, but the programme has continued online throughout 2020.

The approach being taken is to:

- review existing internal erosion (IE) initiated breach models with the most promising few (with potential for industry application) selected for closer analysis.

- review available laboratory, field and case study data in order to identify a number of data sets that can be used for model performance assessment and validation.

- invite international organisations to participate in a programme of model review, testing and validation.

- implement a programme of both 'blind' and 'aware' model testing, with results shared and assessed transparently by the international team.

- review and conclude as to the capabilities and potential of existing internal erosion initiated breach models

The overall objective of the project is to identify and assess the performance of industry applicable breach models which can simulate breach formation and growth arising from internal erosion.

\section{Creation of the working group and selection of breach models}

The structure adopted for implementation of the project was that EDF funded implementation of the project framework, with any modellers participating at their own cost.

The project is of interest to both model developers and model users in that the transparent assessment of model performance both provides a mechanism to openly compare and assess performance as well as a means to understand in detail what each model does and how it may be applied.

To establish both the working team and the range of breach models, the project was openly advertised through various workshops, conferences and online networks.

\subsection{Breach model definition}

The objective of the project is to identify and assess the performance of industry applicable breach models which can simulate breach formation and growth arising from internal erosion. The term 'industry applicable' is defined as model(s) which:

- are commercially available, ideally with some form of support

- use parameters which can be reasonably estimated or measured

- takes seconds or minutes to run rather than hours or days 
The definition of an 'internal erosion initiated' breach model is a model which simulates growth of internal erosion through to complete open breach failure of the dam or levee. It is not sufficient to simply predict that a form of internal erosion might occur, or to predict initiation but not growth to open breach (unless simply linking with another model to provide an overall solution). Hence this requires the model to:

- $\quad$ either predict absolute initiation processes (e.g., ICOLD bulletin 164 (ICOLD 2015; ICOLD 2016)) or assume an initial 'pipe' through the structure, AND:

- predict growth of that pipe with any associated erosion processes, and hence:

- allow for upstream and downstream hydraulic boundary conditions.

- may or may not include internal soil conditions / pore pressures etc.

\subsection{Breach models under assessment as part of the performance evaluation programme}

Table 1 provides a summary of the breach models being evaluated as part of this project.

\begin{tabular}{|c|c|c|}
\hline Model & Modeller & $\begin{array}{l}\text { Organisation / } \\
\text { Country }\end{array}$ \\
\hline AREBA & $\begin{array}{ll}\text { Myron } & \text { van } \\
\text { Damme } & \end{array}$ & $\begin{array}{l}\text { TU Delft, The } \\
\text { Netherlands }\end{array}$ \\
\hline \multicolumn{3}{|c|}{ For more info contact: myron.van.damme@,rws.nl } \\
\hline DL BREACH & Weiming Wu & $\begin{array}{l}\text { Clarkson Uni, } \\
\text { USA }\end{array}$ \\
\hline \multicolumn{3}{|c|}{ For more info contact: wwu@clarkson.edu } \\
\hline EMBREA & Mohamed Hassan & $\begin{array}{l}\text { HR } \\
\text { Wallingford, } \\
\text { UK }\end{array}$ \\
\hline \multicolumn{3}{|c|}{ For more info see: www.dambreach.org } \\
\hline RUPRO & André Paquier & $\begin{array}{l}\text { INRAE, } \\
\text { France }\end{array}$ \\
\hline \multicolumn{3}{|c|}{ For more info contact: andre.paquier@inrae.fr } \\
\hline WinDAMC & Sherry Hunt & $\begin{array}{l}\text { USDA-HERU, } \\
\text { USA }\end{array}$ \\
\hline \multicolumn{3}{|c|}{ For more info contact: sherry.hunt@usda.gov } \\
\hline OvaBreach & $\begin{array}{l}\text { Veronika } \\
\text { Stoyanova }\end{array}$ & $\begin{array}{l}\text { ARUP, } \\
\text { UK }\end{array}$ \\
\hline
\end{tabular}

\subsection{Organisations participating in the performance evaluation programme}

Table 2 provides a summary of the organisations involved in the project team - i.e., participating in the modelling programme, analysis of results etc.

\begin{tabular}{|l|l|l|}
\hline Ref & Organisation & Country \\
\hline 1 & Electricité de France (EDF) & France \\
\hline 2 & HR Wallingford (HRW) & UK \\
\hline 2 & Geophy Consult sarl (Geophy) & France \\
\hline 3 & $\begin{array}{l}\text { Institut National de Recherche } \\
\text { pour L'Agriculture, } \\
\text { L'Alimentation et } \\
\text { L'Environnement (INRAE) }\end{array}$ & France \\
\hline 4 & $\begin{array}{l}\text { USDA Agricultural Research } \\
\text { Service Hydraulic Engineering } \\
\text { Research Unit (HERU) }\end{array}$ & USA \\
\hline 5 & Bureau of Reclamation (USBR) & USA \\
\hline 6 & $\begin{array}{l}\text { US Army Research and } \\
\text { Development Center (ERDC) }\end{array}$ & USA \\
\hline 7 & $\begin{array}{l}\text { Brno University of Technology } \\
\text { Czech } \\
\text { Republic }\end{array}$ \\
\hline 8 & Geosyntec Consultants Inc. & USA \\
\hline 9 & ARUP & UK \\
\hline 10 & Clarkson University & USA \\
\hline 11 & TU Delft / Rijkswaterstaat & Netherlands \\
\hline
\end{tabular}

Table 2. Summary of organisations participating in the review programme

\section{Model performance validation programme and process}

The approach for implementing the programme was agreed at the initial workshop (Stillwater, October 2019) and is outlined below.

\subsection{Approach for performance analysis}

Managing the modelling programme, comprising definition of test cases, collation of results, preliminary results analyses, chairing of discussion sessions and report drafting was undertaken by Mark Morris, on behalf of EDF.

A programme of different test cases was progressively established (detailed below) through a series of different phases of modelling work. Under each phase of modelling work, and as with the earlier DSIG breach modelling project, a programme of 'blind' and 'aware' modelling was agreed.

'Blind' modelling is where test conditions are defined for the modellers, but data relating to what actually happened - whether theoretical, laboratory, field or case study event - is not shared. Results are collated before modellers are then asked to undertake 'aware' modelling, where results of the actual event are shared, and modellers can see how they may improve their model predictions accordingly. The advantage of undertaking blind and aware modelling is that it helps:

- identify whether performance is a function of the model or the modeller or both.

- identify whether the model could have produced correct results using parameters within an acceptable range of values. 


\subsection{Breach modelling programme}

A total of 4 phases of modelling work were agreed, comprising Phase $0,1,2$ and 3 . Phase 0 was intended as a single, hypothetical test case to allow the modelling process to be tested and any corrections made prior to implementing a programme of test cases using real laboratory, field and failure case data sets. The data sets for each phase of work was defined during the preceding phase of work, to allow for flexibility in approach.

The overall programme schedule was:

- Summer 2019 Model review; data review; establishing the project team and models.

- October 2019 Kick off workshop - ARS-HERU, Stillwater, OK. USA.

- Spring 2020 Templates, model descriptions etc.

- Spring 2020 Phase 0 Hypothetical test case.

- Summer 2020 Review Phase 0 / Launch Phase 1.

- Winter 2020/21 Review Phase 1 / Launch Phase 2.

- Spring 2021 Review Phase 21 Launch Phase 3.

- Autumn 2021 Review Phase 3.

- Winter 2021 Conclusions and Report.

\subsection{Breach modelling test cases}

Phase 0 Test Case

Under Phase 0 , a hypothetical test case was established based upon an actual UK reservoir site dating from 1884, with a history of seepage problems. The dam comprised a clay core with earthfill. Soil descriptions and grading curves were provided. In 1999 a sinkhole appeared above an outlet culvert and from 2002 the normal operating water level was reduced by $7 \mathrm{~m}$.

The dam height is approximately $20 \mathrm{~m}$, crest width $4 \mathrm{~m}$ and crest length $250 \mathrm{~m}$. The retained reservoir has approximate dimensions of $400 \mathrm{~m}$ by $200 \mathrm{~m}$, retaining $\sim 200000 \mathrm{~m}^{3}$ of water. See Figure 1 .

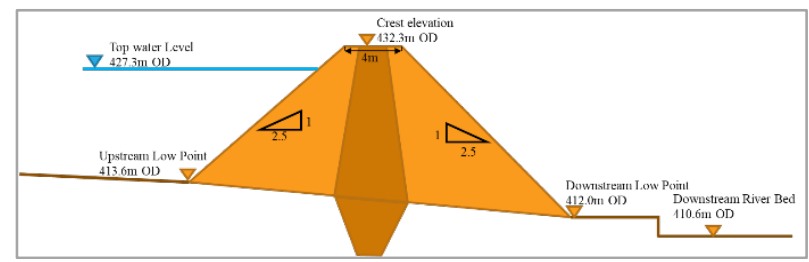

Figure 1. Phase 0 hypothetical test case

For the breach modelling test, an inflow hydrograph was provided, and it was assumed that failure was initiated through pipe flow initiated at a level a few metres above the foundation.

As a hypothetical test case, no data was available to compare against model predictions. The purpose of the test was to ensure that the process for exchange and analysis of data worked well and to compare differences between model predictions.
Phase 1 Test Cases

Under Phase 1, four different test cases were specified. These comprised:

- Modified hypothetical (from Phase 0)

- EC IMPACT project test case

- ARS-HERU Stillwater test cases P1 and P4

The original hypothetical test case was modified and retested to see whether we could differentiate more clearly between model performance and modeller assumptions. Where parameters are not defined, and modellers are required to make expert judgements, these invariably lead to different results. When this is combined with a variable inflow hydrograph (as in the original case), this magnifies the differences. Hence the modified hypothetical test case included a simplified steady inflow hydrograph, simplified geometry and clarified some soil parameters.

The IMPACT Project test case was taken from the set of large-scale field tests performed in Norway as part of the IMPACT project, which ran from 2002-2005. Details of the test data can be found in Hassan \& Morris, 2008. This test (Test 3-03) was undertaken in October 2003 on a homogeneous levee section, $4.3 \mathrm{~m}$ high constructed from moraine material. Internal erosion was initiated near the base using a slotted pipe set in a bed of sand passing through the structure. See Figures 2, 3 and 4.

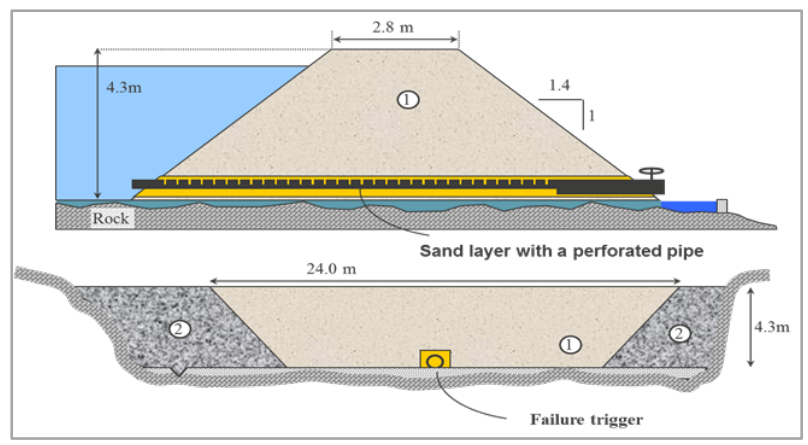

Figure 2. IMPACT Project Test 3-03

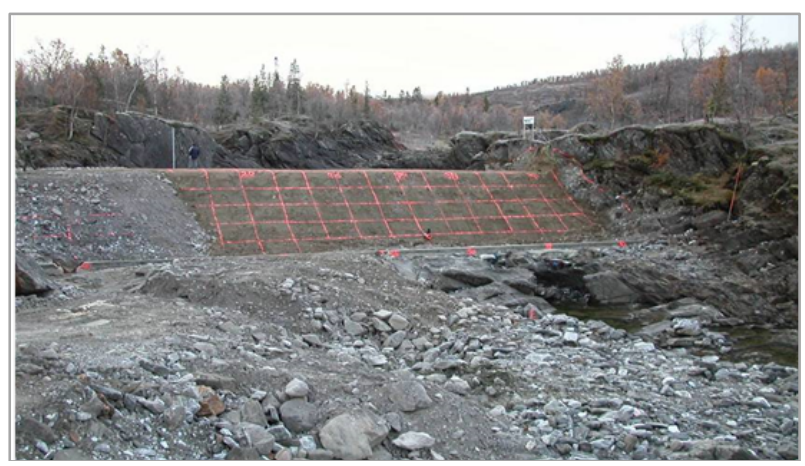

Figure 3. IMPACT Project Test 3-03 constructed 


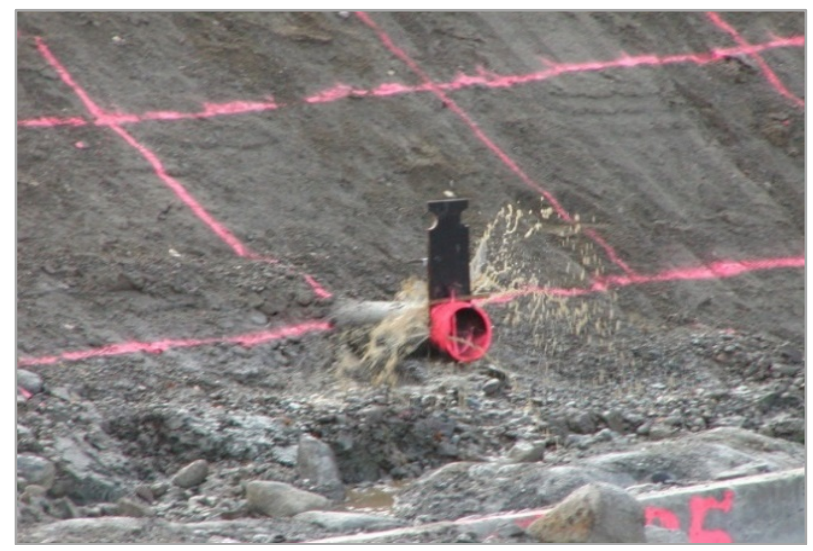

Figure 4. IMPACT Project Test 3-03 pipe initiation control

For the IMPACT test case, photos and records of water levels, estimated flows etc were available for comparison with breach model predictions.

ARS-HERU provided two test cases for modelling under Phase 1. These were test cases P1 and P4 respectively. These cases were similar in terms of size, loading and failure initiation, but constructed using different soils, and hence resulting in different soil erodibility. Figure 5 below shows the setup for Test P1.
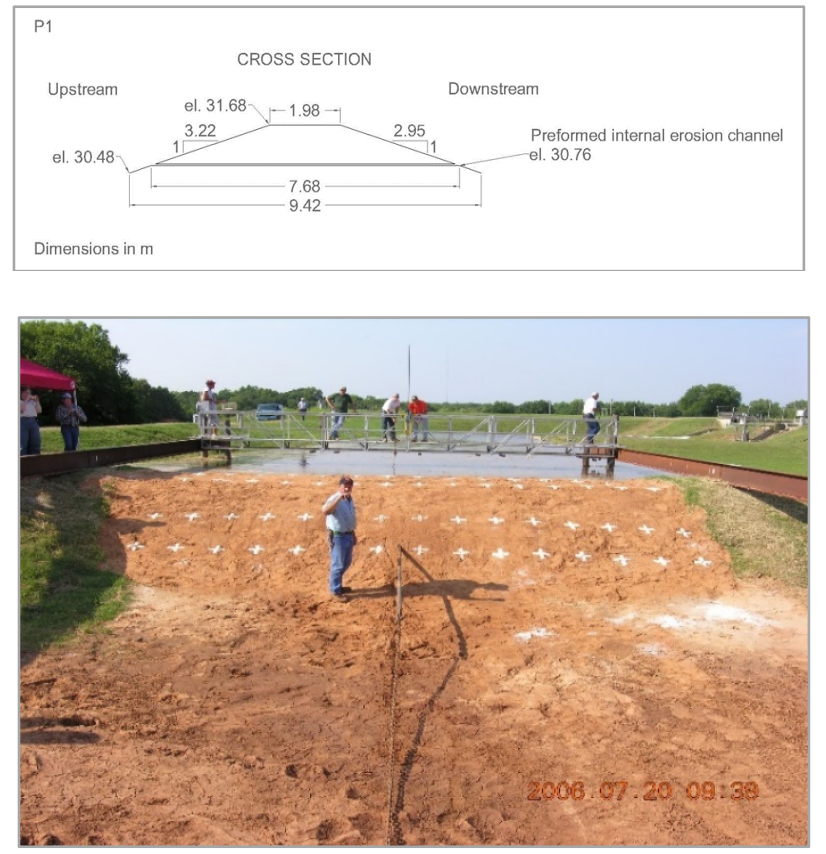

Figure 5. ARS-HERU Test P1

Both P1 and P4 tests were initiated by removing the steel pipe set into the levee body, creating a hole through the structure of $\sim 4 \mathrm{~cm}$ diameter. The difference soils between the two tests meant that the P1 grading had a $\mathrm{d} 50$ of $0.13 \mathrm{~mm}$, including $8 \%$ clays, whilst the $\mathrm{P} 4$ grading had a d50 of $0.02 \mathrm{~mm}$, including $35 \%$ clays. In fact, the erodibilty of the $\mathrm{P} 4$ soil was sufficiently resistant that breach failure did not occur. Figures 6 and 7 below show the different rates of erosion observed for the two tests. This provides an interesting challenge for the breach models, in testing their ability to predict no failure as well as failure.

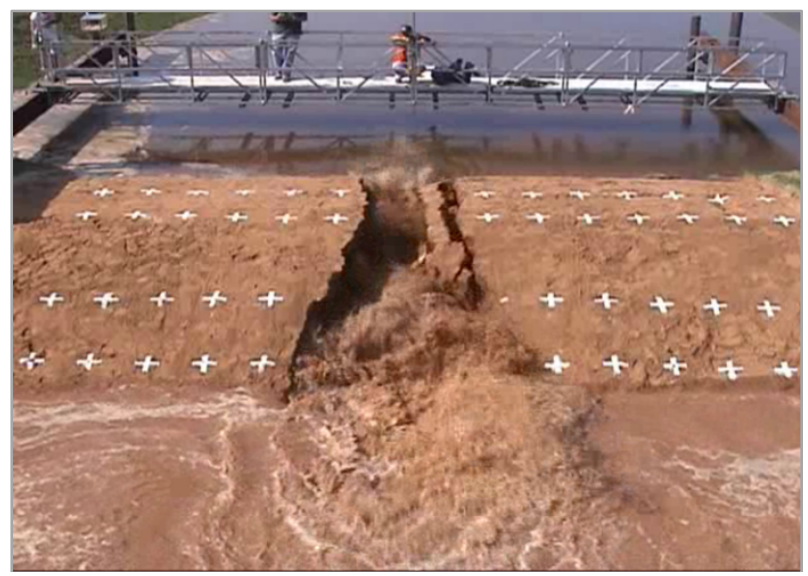

Figure 6. ARS-HERU Test P1 after 14 minutes

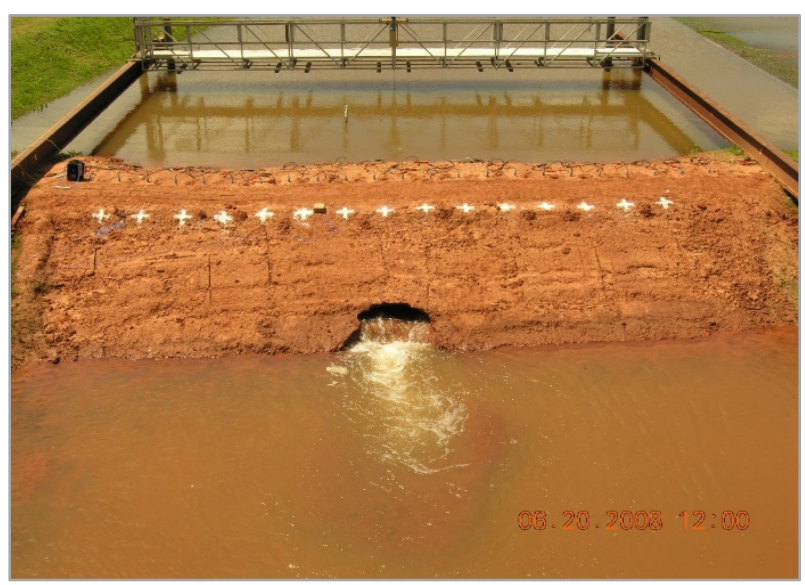

Figure 7. ARS-HERU Test P4 after 72 hours

\section{$\underline{\text { Phase } 2 \text { Test Cases }}$}

Having considered hypothetical and field test cases for Phase 0 and Phase 1 modelling, the focus for the Phase 2 test cases were real dam failure case studies. Two cases were identified from the EDF Database of Dam Incidents and Failures (EDF, 2021). This database offers an invaluable source of case study data since for each case entry, there is a collection of reports, publications and data all of which have been carefully reviewed for consistency. This has allowed conclusions to be drawn for each case study as to the most likely order of events, key processes and key data.

The two dam failure cases selected as test cases were:

- Lawn Lake Dam (Larimer County, Colorado, US)

- Big Bay Dam (Lamar County, Mississippi, US)

Lawn Lake Dam was constructed in 1903 and failed in 1982. At the time of failure it was $\sim 8 \mathrm{~m}$ high and $\sim 200 \mathrm{~m}$ long, retaining $\sim 1 \mathrm{Mm}^{3}$ of water. Internal erosion initiated alongside an outlet pipe was considered the most likely cause of failure (Figure 8). 


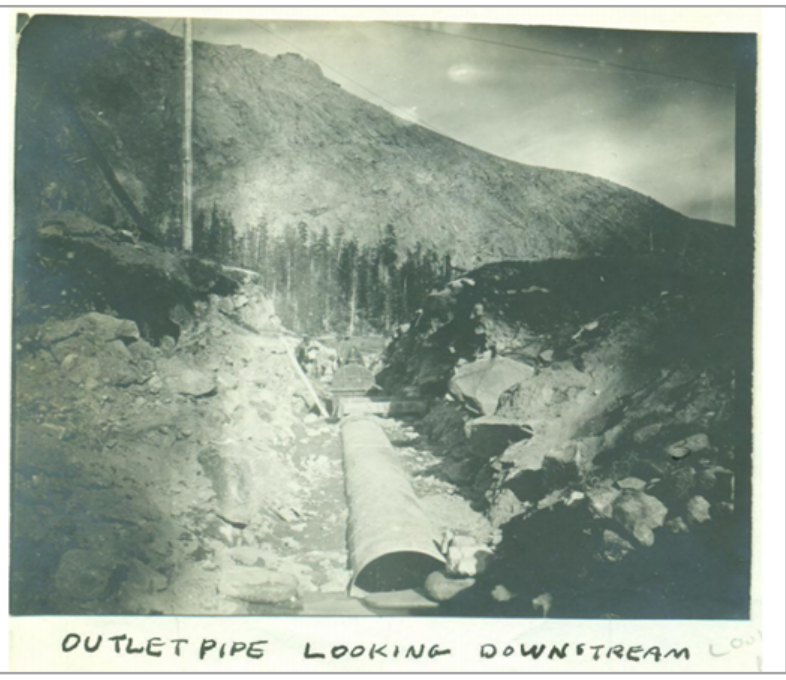

Figure 8. Lawn Lake Dam breach (Photo: State Engineers Office (SEO) file, 1903 photo)

In contrast, Big Bay Dam was constructed in 1991 and failed only 13 years later in 2004, again due to piping. Higher than expected permeability of the core and a failure to tie this properly to the foundation resulted in pipe formation close to an outlet conduit set into the foundations. Big bay Dam was $\sim 17 \mathrm{~m}$ high, $600 \mathrm{~m}$ long and released $\sim 17.5 \mathrm{Mm}^{3}$ of water.
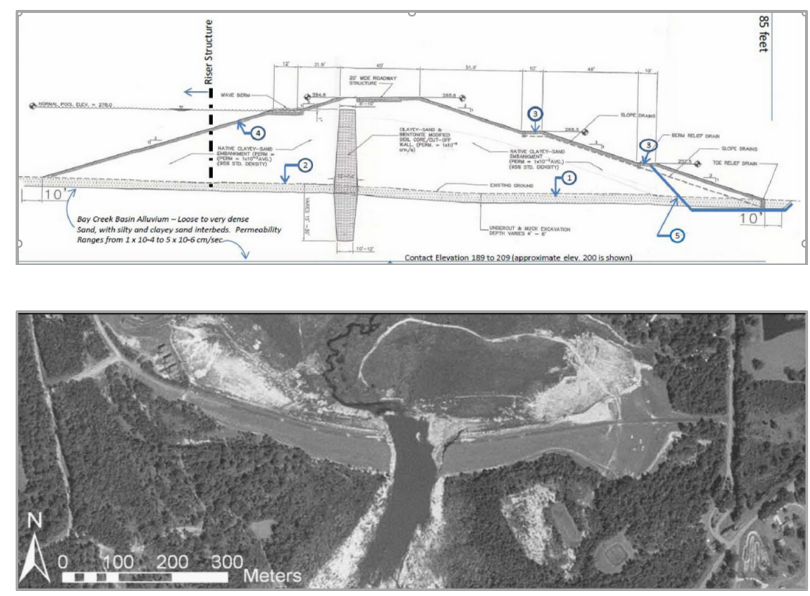

Figure 9. Big Bay Dam breach (Photos: Ferguson et al (2004))

\section{Initial findings}

Since the performance analysis programme is still ongoing (roughly halfway through) we are not able to present final conclusions, although some interesting observations can be seen - as summarised below.

1. From the outset under Phase 0 , it became clear that modeller assumptions (i.e., how to simulate a particular case, any simplifying assumptions and any assumptions needed for model parameter values) can have a very significant impact on model results.

2. Even with experienced modellers, understanding how to use different models and how to extract data from different models can cause problems.
3. Care is needed to ensure that model results are clearly understood. What is meant by terminology used in one model may not necessarily be the same as in the next. For example, breach depth may relate to the physical height of the breach opening, or the elevation of the breach opening. Breach width may refer to width at the crest, at the dam toe or at a moving location in-between. Each of these differences makes direct comparison inappropriate!

4. A wide range of modelling results can be seen for each of the test cases so far. An example is shown in Figure 10 below.

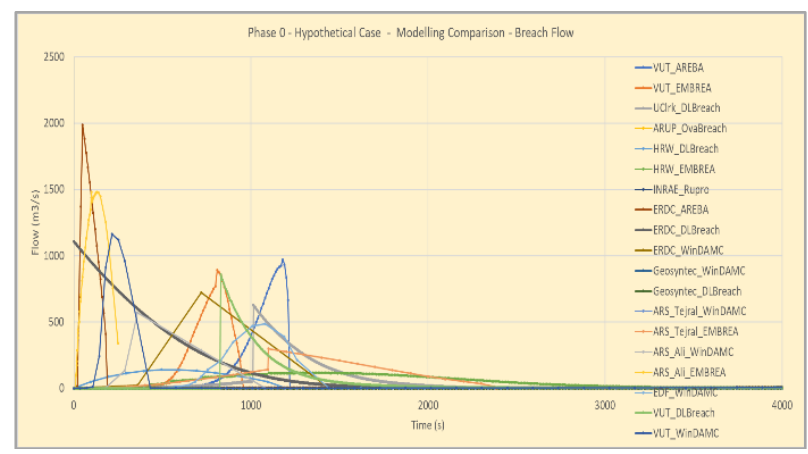

Figure 10. Example distribution of modelling results (Phase 0 Hypothetical Test Case, Flow Hydrographs)

When drawing conclusions from these results it is important, wherever possible, to separate model and modeller effects, and to ensure correct or at least consistent model use. Subsequently, different aspects of the modelling process can be identified in the results and we should be able to home in on which models perform best under which circumstances. Different model aspects might include, for example, timing of initiation, rate of pipe growth, timing and nature of pipe roof failure (transition to open breach), open breach formation rate, breach widening rate etc.

Some preliminary conclusions at this stage (which naturally focus on more general issues rather than model performance since the assessment programme is incomplete) include:

1. Modellers need to have a good understanding of both the situation being modelled and how to use the breach model in order to get reasonable results.

2. Developers should pay attention to model usability to ensure that modellers are better guided through the simulation process - to avoid misapplication of the models.

3. Developers should ensure clear explanations of all output parameters are given and ideally offer more flexible ways for modellers to define the nature of the output required (e.g., seamless transitions between modelling units; user definition of breach width and depth measurements etc.).

4. Where key parameters - such as soil erodibility are missing - modellers need to take time to ensure that the values they use really are representative. Variations in some parameters can significantly affect outcomes. Where load conditions are time variable, errors or changes in predicted breach growth can be 
magnified through interaction with the time changing load conditions, leading to very poor results.

\section{Remaining programme and process}

At the time of drafting, we are roughly halfway through the programme of model performance testing and drafting of observations and conclusions has not been undertaken. Despite COVID-19 the modelling programme remains broadly on schedule to for completion by the end of 2021 .

At the end of the Phase 2 modelling analysis, model performance observations will be reviewed to identify potential trends in behaviour; the Phase 3 modelling programme will then be developed to help confirm or dispel such trends.

During the last quarter of 2021, the team will focus upon summarising observations and drawing overall conclusions from the performance analyses. The report detailing these conclusions will be made publicly available by EDF.

\section{Acknowledgements}

Whilst the framework to implement this project is funded by EDF, participation by each of the modellers whether as a model developer or a model user (or both) has been funded by their individual organisations. This open cooperation is appreciated, and the only way in which this programme of work could be completed.

The various test cases used have come from a combination of sources. The additional effort needed to provide this information, including photos, is recognised in particular by:

- Hypothetical Test Case - ARUP (Veronika Stoyanova)

- $\quad$ IMPACT Test Case - HR Wallingford (Mohamed Hassan)

- P1 \& P4 Test Cases - USDA, ARS-HERU (Ron Tejral / Abdelfatah Ali / Sherry Hunt)

- Lawn Lake and Big Bay Dam Failures - EDF Failure Database - EDF / Geophy Consult (Jean-Robert Courivaud / Pierre Squillari)

\section{References}

1. Bureau of Reclamation (2017). Evaluation of Numerical Models for Simulating Embankment Dam Erosion and Breach Processes. Dam Safety Technology Development Program, Report DSO2017-02.

2. EDF (2021). Database of dam incidents and failures. www.dfdb.eu

3. Ferguson, K.A., Anderson, S., \& Sossenkina, E. (2004). Reexamination of the 2004 Failure of Big Bay Dam, Mississippi. USSD Annual Conference. San Francisco, CA: United States Society on Dams

4. ICOLD (2015). Internal erosion of existing dams, levees and dikes, and their foundations. Volume 1: Internal erosion processes and engineering assessment. ICOLD Bulletin 164. International
Commission on Large Dams, Paris. Preprint 19 February 2015 from: http://www.icold-cigb.org

5. Hassan, M. A. A. M. \& Morris, M. W. (2008). IMPACT Project field tests data analysis. FLOODsite Report T04-08-04. UK: See www.impact-project.net and www.floodsite.net

6. ICOLD (2016). Internal erosion of existing dams, levees and dikes, and their foundations. Volume 2: Investigations, testing, monitoring and detection, remediation and case histories. Internal erosion processes and engineering assessment. ICOLD Bulletin 164. International Commission on Large Dams, Paris. Preprint 5 February 2016 from: http://www.icold-cigb.org 